\title{
ESSE POEMA É UMA PERFORMANCE: UMA ANÁLISE DA RELAÇÃO ENTRE PRODUTOR E EU LÍRICO EM "PARQUE DAS RUÍNAS" DE MARÍLIA GARCIA, A PARTIR DE UMA ABORDAGEM SISTÊMICA
}

\author{
ESSE POEMA É UMA PERFORMANCE: AN ANALYSIS OF \\ THE RELATION BETWEEN PRODUCER AND LYRIC SELF IN \\ "PARQUE DAS RUIINAS" BY MARIILIA GARCIA BASED ON A \\ SYSTEMIC APPROACH
}

\author{
Mariane Pereira Rocha' \\ [http://orcid.org/0000-0002-0126-8063] \\ Aulus Mandagará Martins ${ }^{2}$ \\ [http://orcid.org/0000-0002-0590-1890] \\ DOI: 10.30612/raido.v15i38.14534
}

\begin{abstract}
RESUMO: O presente artigo objetiva discutir a poesia de Marília Garcia em parque das ruínas (2018) a partir da abordagem sistêmica proposta por Itamar Even-Zohar (2013), com ênfase na reflexâo sobre o lugar do produtor dentro da poesia contemporânea e sobre as fronteiras entre eu lírico e eu biográfico na obra de Garcia. Entende-se que essa poesia é um lugar privilegiado para discutir determinados aspectos de organizaçâo do sistema literário, bem como que essa lírica impossibilitaria uma abordagem mais convencional, cujo enfoque fosse somente aquilo que é intrínseco ao texto, visto que a poeta está em constante diálogo seja com outros poetas e tradutores, seja com vídeos e blogs, seja com seus livros publicados anteriormente.
\end{abstract}

Palavras-chave: Marília Garcia; Sistema literário; Poesia contemporânea.

ABSTRACT: This article seeks to discuss the poetry of Marília Garcia in parque das ruínas (2018) from the systemic approach proposed by Itamar Even-Zohar (2013), with an emphasis on reflection on the place of the producer within contemporary poetry and on the boundaries between lyrical and biographical in Garcia's work. It is understood not only that Marília's poetry is a privileged place to discuss certain aspects of the organization of the literary system, but also that this lyric would preclude a more conventional approach, whose focus was only that which is intrinsic to the text, since the poet is in constant dialogue, whether with other poets and translators, with videos and blogs, or with her previously published books.

Keywords: Marília Garcia. Literary system. Contemporary poetry.

\footnotetext{
1 Instituto Federal Sul-rio-grandense (IFRS).

2 Universidade Federal de Pelotas (UFPel).
} 
Marília Garcia, poeta carioca, publicou seu primeiro livro, 20 poemas para seu walkman, em 2007. Onze anos depois, escreve seu sexto livro de poemas, parque das ruínas (2018) que, assim como os livros anteriores, apresenta poemas fragmentados, os quais se aproximam da oralidade, da narraçăo e estabelecem diálogos com outras áreas, como as artes, o cinema, a fotografia e a filosofia. Há, no entanto, algumas características que diferenciam essa produçăo das demais, por exemplo, o fato de, apesar de todos os livros de Garcia terem uma conexâo forte com as imagens, parque das ruínas ser o primeiro a integrar fotografias e outras materialidades visuais aos poemas. Anteriormente, a aproximaçăo com o visual se dava apenas através da mençâo às imagens ou ainda da incorporaçăo das mesmas à sintaxe dos poemas.

Além disso, os três poemas que compóem a obra parque das ruínas (o primeiro, mais longo, com o mesmo título do livro, o segundo chamado "o poema no tubo de ensaio" e o terceiro, espécie de anexo, chamado "p.s.") ultrapassam a materialidade do livro, já que repetem e modificam versos que já foram anteriormente divulgados ao público, sejam em outros livros, sejam em eventos literários. Assim, Marília Garcia parece desestabilizar algumas das relaçôes de poder dentro da literatura, já que frequentemente atribui ao produto-poema um papel tăo significativo quanto o do produtor-poeta. Esse agora nâo somente está inserido no texto, através de uma poesia essencialmente autorreferencial, como também detém o poder sobre seus poemas mesmo após a publicaçâo final, já que os textos retornam modificados em livros diferentes, constituindo, assim, uma lírica que nunca está finalizada nela mesma.

Entende-se, nesse sentido, que a poesia de Marília é um lugar privilegiado para discutir determinados aspectos de organizaçâo do sistema literário (Even- Zohar, 2013a), entre eles a relaçăo entre produtor, eu lírico e eu biográfico. Essa lírica impossibilitaria, ainda, uma abordagem mais convencional, cujo enfoque fosse somente aquilo que é intrínseco ao texto, visto que a poeta faz inúmeras referências a outros poetas e tradutores, a vídeos e blogs e aos seus próprios livros. Dessa forma, o objetivo desse artigo é fazer uma análise da obra parque das ruínas (2018) a partir da abordagem sistêmica de Even-Zohar (2013a), refletindo especialmente sobre o lugar do produtor na poesia contemporânea. Para o autor, a abordagem sistêmica vai, justamente, permitir que se estabeleça uma nova relaçâo com o texto literário:

a ideia de sistema tornou possível năo só explicar adequadamente fenômenos "conhecidos", mas, também, desconhecidos. O funcionalismo alterou profundamente tanto as estruturas como os métodos, as perguntas e as respostas de todas as disciplinas em que foi introduzido (EVEN-ZOHAR, 2013b, p. 1).

Observamos que, se a modernidade, pautada nas discussôes estruturais, instaurou a morte do autor em detrimento de um estudo literário focado no texto e nas suas estruturas, a discussăo sistêmica parece reinserir o produtor na discussăo sobre o texto literário. De acordo com Even-Zohar,

Tem havido uma grande ausência de teorias da literatura do ponto de vista da produçáo. Infelizmente, quando a tradiçáo cultural de colocar o escritor no centro da literatura foi abolida, e começou a impor-se o estudo "textocêntrico", os velhos modelos exegéticos invadiram os novos métodos "interpretativos" que surgiram para concentrar-se na "compreensăo do texto". Esta classe de "compreensăo", 
certamente, deu por certo o que o texto existe de alguma maneira que năo é necessário questionar, muito menos pesquisar, pois está "aí", e tudo o que nos fica (a nós mortais) é decifrar seus segredos (EVEN-ZOHAR, 2013a, p. 31).

Sendo assim, o escritor, dentro de uma lógica sistêmica, ocupa um papel importante, visto que todos os elementos do sistema literário desempenham funçâo significativa e se relacionam, sem hierarquia entre eles, uma vez que “o 'texto' já nâo é o único, nem necessariamente o mais importante em nenhum sentido, aspecto, ou inclusive produto desse sistema" (EVEN-ZOHAR, 2013a, p. 30).

Além disso, a noçăo de produtor que Even-Zohar discute vai além daquele escritor/ autor que produz textos, mas também inclui todo agente literário que efetivamente mantém uma produçăo política e interpessoal de imagens, estados de ânimo e opçôes de açăo. E é nesse sentido que tal noçăo parece adequada ao falarmos do poeta contemporâneo, visto que uma definiçăo a qual o colocasse apenas no lugar do escritor que entrega seu texto pronto ao leitor náo daria conta de abarcar a complexidade daquilo que a contemporaneidade exige da figura do poeta. ${ }^{3}$

Ao pensar na poesia de Marília Garcia através desta abordagem sistêmica sugerida por Even-Zohar, conseguimos ser capazes de entender alguns aspectos da obra que uma leitura focada apenas no intrínseco ao texto năo daria conta. parque das ruínas (2018) está em diálogo explícito com toda a produçāo poética da autora, o que podemos perceber já no primeiro poema do livro, de mesmo título. Esse poema, com algumas alteraçôes, havia sido lido pela poeta na Casa de Rui Barbosa em abril de 2017, com o título "tem país na paisagem?". Na ocasiăo, Garcia fez a leitura dos versos do poema ao mesmo tempo em que reproduzia em um projetor uma série de fotos. Tal leitura está agora disponível no canal do YouTube ${ }^{4}$ e da poeta e conta com a seguinte descriçăo: “Tem país na paisagem?' passou a se chamar 'Parque das ruínas' e integra novo volume da autora

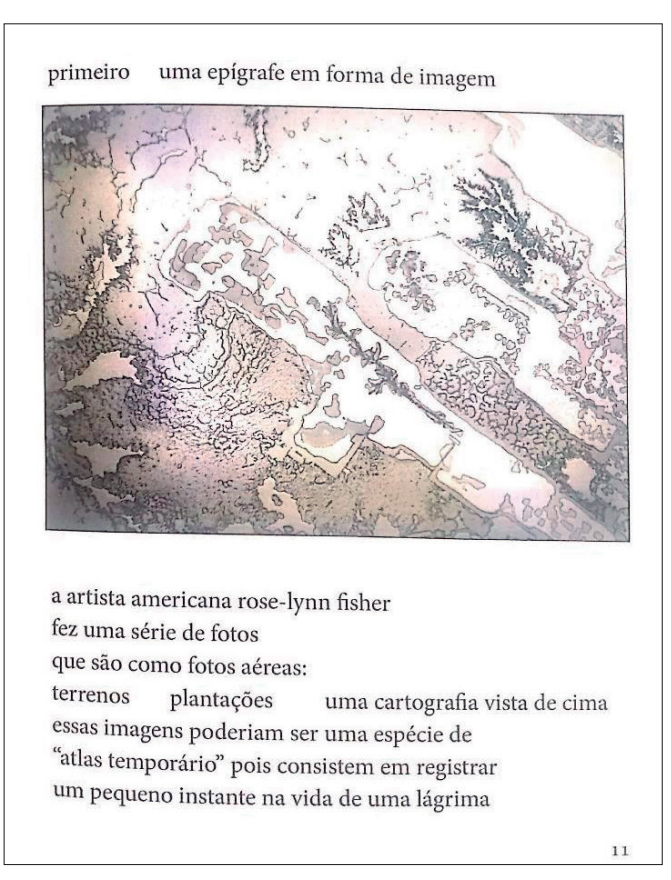

(GARCIA, 2018, p. 11) publicado pela editora Luna Parque (2018)". No mesmo ano, o poema "tem país na paisagem?" compôs o livro Câmera lenta (2017), vindo acompanhado da descriçấo: "(versăo compacta)". Nessa versăo compacta de cento e vinte seis versos, năo há a presença de fotos, porém se manteve o eixo do poema que foi lido na

3 É interessante ainda considerar, conforme nos lembra Beatriz Resende, que o escritor contemporâneo é também uma figura pública, cuja vida pessoal e interesses importam e săo, constantemente, compartilhados com os leitores através das redes sociais e dos eventos literários. Segundo a autora, festas e festivais literários mostram "uma nova habilidade dos escritores contemporâneos - para o bem e para o mal - de serem também uma espécie de performer, revelando a persona do autor ou mesmo recusando- se a exercer este papel, como fez o genial J.M. Coetzee, ganhador do prêmio Nobel" (RESENDE, 2008, p. 16).

4 https://www.youtube.com/watch?v=qEQfXg4b9Ko 
Casa de Rui Barbosa: um eu lírico que, todo dia às 10 horas da manhă, fotografava a mesma ponte. Em "Parque das ruínas", encontramos, entăo, a mesma versăo estendida que já havia sido lida na ocasiăo, desta vez, acompanhada das fotografias que, se no evento haviam sido projetadas, aqui săo reproduzidas entre os versos e estrofes, compondo o conteúdo do poema, como veremos posteriormente.

Há, aliado a isso, fortemente marcada durante todo o poema, a presença de um "eu", o qual é manifestado em dois planos. No primeiro, há um relato de experiência, através do qual o eu lírico conta alguns acontecimentos de sua vida, incluindo o que a levou a escrever o texto:

gostaria de começar contando o que aconteceu

no dia em que recebi uma encomenda para escrever este texto eu estava no rio de janeiro

e tinha ido ver uma exposiçăo do jean-baptiste debret num museu chamado "chácara do céu"

em determinado momento da exposiçăo

eu queria tomar um café mas lá năo tinha café para tomar um café

era preciso sair da "chácara do céu"

e ir ao museu ao lado chamado "parque nas ruínas" (GARCIA, 2018, p. 15).

No outro plano, há inserçôes de trechos do diário do eu lírico, os quais estāo postos com a fonte em itálico e com um subtítulo entre colchetes, seguido de uma inscriçăo da data e horário. Em ambas partes - relato e diário - fica sugerida a possibilidade que este eu seja o eu biográfico de Marília Garcia. Por exemplo, na terceira parte do poema, a poeta relata o que a levou ao movimento de tirar diariamente as fotos da pont marie, em Paris:

em 2015 fiz uma residência na frança

ao chegar lá comecei a tomar notas:

para entender o que estava vendo para inventar uma rotina (...)

a pergunta que eu fazia era a seguinte: como lidar com o próprio lugar?

$[\ldots]$

como eu năo sabia o que eu queria entender

decidi começar um diário que tinha apenas uma regra: todos os dias deveria tirar uma fotografia

do mesmo lugar / na mesma hora

e partir dela para fazer o diário (GARCIA, 2018, p. 23).

Sabemos que essa experiência pode se relacionar com a experiência biográfica de Marília, visto que, na contracapa do livro, encontramos a seguinte informaçăo: "A autora agradece ao Prêmio Icatu de Artes que lhe concedeu uma residência na Cité Internationale des Arts, entre dezembro de 2014 e julho de 2015, por onde estes dois textos passaram". A poeta, entăo, esteve na França e possivelmente conviveu com a ponte a qual ela faz referência no poema. 
Os trechos citados acima săo, ainda, precedidos por uma fotografia da ponte, sozinha, na parte superior da página, em um ângulo no qual podemos ver o nome dessa em primeiro plano, no que parece uma tentativa de enfatizar o lugar que foi escolhido pela poeta:

Ao aliar uma fotografia da ponte que está citando aos versos do poema, a hipótese da predominância de um eu biográfico se fortalece, visto que as fotografias podem ser lidas como uma tentativa de dar veracidade à informaçăo que está sendo contada. As fotografias sâo, afinal, ainda entendidas como comprovantes de algo que foi vivido ou experienciado, um comprovante do real, já que, desde sua invençăo no começo do século XIX, elas foram entendidas como uma representaçăo da "verdade". Susan Sontag (2004) afirma que "a fotografia tem a reputaçáo pouco atraente de ser a mais realista e, portanto, a mais fácil das artes miméticas" (SONTAG, 2004, p. 34). É justamente por essa suposta aproximaçấo da fotografia com a realidade que ela vai ser associada àquilo que é verdadeiro. Essa "reputaçâa" que a fotografia carrega continua cercando-a até os dias de hoje, apesar de todas as mudanças que o processo fotográfico sofreu ao longo das décadas, e parece irromper de uma característica inerente à sua própria técnica: a impossibilidade de existir sem um referente, seja ele objeto, pessoa ou paisagem. Existe, de fato, uma Pont Marie em Paris e, independente das fotos terem sidas ou náo tiradas pela poeta, o gesto de incluí-las no poema confere a ele uma possibilidade de real:

A poeta, entâo, ao utilizar as fotografias, explicita uma possível vinculaçấo com a realidade, que daria determinada verossimilhança à experiência que narra. Na quinta parte do poema, o eu lírico problematiza, ainda, o fato de utilizar fotografias

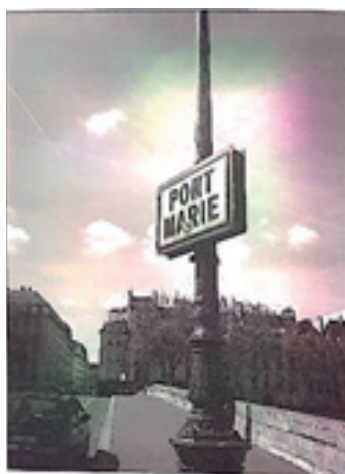

(GARCIA, 2018, p. 22)
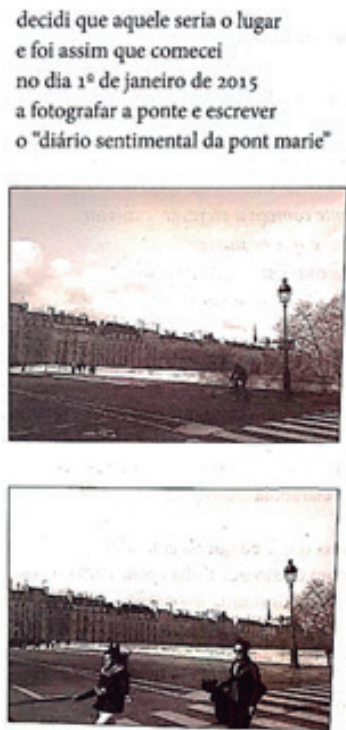

(GARCIA, 2018, p. 24). junto ao poema:

aqui faço um intervalo

para um pequeno comentário sobre esse trabalho:

[eu costumo falar este texto mostrando imagens

săo ao todo 240 imagens]

[uma vez me perguntaram se esta apresentaçăo

náo estava muito ilustrativa]

[ - você fala em ruína

e insere uma imagem de ruína]

[você fala em ponte

e traz várias imagens da mesma ponte]

[qual a relaçâo das imagens

com o texto?]

e eu năo soube responder (GARCIA, 2018, p. 40, grifos da autora). 
Aqui, outro uso da fotografia é revelado: a fotografia enquanto ilustraçăo daquilo que se fala. De fato, grande parte das fotografias utilizadas pela poeta durante seus poemas repetem informaçóes que já estăo dadas pelo texto verbal. Apesar disso, dificilmente poderíamos afirmar que a funçâo das fotografias em "Parque das ruínas" é apenas ilustrar aquilo que se fala, visto que o eu lírico está o tempo todo elaborando essa utilizaçâo das fotografias, em um processo reflexivo sobre seu funcionamento. A própria motivaçáo para as fotografias da pont marie surge de filmes que discutem também os usos do dispositivo fotográfico:

tive vontade de fazer o "diário sentimental da pont marie" depois de ter visto alguns filmes

que enumero aqui

primeiro smoke (cortina de fumaça)

o personagem principal auggie é dono de uma tabacaria e todos os dias às $8 \mathrm{~h}$ da manhă durante muitos anos ele tira uma foto da esquina da tabacaria

tem mais de 4.000 fotos

numa manhă

auggie mostra as fotos para paul um velho amigo a princípio o amigo acha que săo todas iguais

afinal partem do mesmo ângulo e enquadram o mesmo ponto

mas aos poucos nessa repetiçăo dos dias paul vê

$[\ldots]$

numa das fotos tirada anos antes ele vêa esposa que já tinha falecido

num momento da vida em que os dois năo estavam juntos

ela aparece congelada num instante

enquanto eu fazia as fotos da pont marie percebi que me interessava em smoke

a insistência a repetiçăo

- seria possível ver a passagem do tempo nesta repetiçăo? (GARCIA, 2018, p. 28-29, grifos da autora).

Além da citaçăo ao filme Smoke, reproduzida acima, o eu lírico aindafala de outro filme que a motivou a escrever o diário: "ao escrever o diário/ também pensava no filme blow-up". Nesse filme, de 1996, dirigido por Michelangelo Antonioni, o protagonista Thomas é um fotógrafo que está fazendo fotos de um casal em uma tarde no parque e, somente mais tarde, ao revelar as fotos e ampliá-las, ele percebe que, no canto de uma das fotografias, há algo que ele entende ser um cadáver. A partir daí, Thomas desenvolve uma obsessâo por essas fotografias e pelo parque e uma trama psicológica se desenvolve. Garcia discute o movimento que acontece neste filme:

ele amplia as fotos ele amplia tanto que perde

o todo - perde a paisagem e chega a um espectro

um borrăo

um fora de foco 
ele estaria alterando a realidade com o seu procedimento?

para tentar ver alguma coisa

ele precisa olhar de muito perto

aqui lembro que o ricardo piglia

analisa algumas fotos de borges quando está quase cego

borges tem um livro diante do rosto

e se coloca muito perto do livro tentando ler:

o olho fixo sobre a página a página contra o olho

ele tenta enxergar no fiapo de luz que ainda resta

este que é um dos maiores leitores do século

diz piglia e no entanto para ler precisar chegar muito perto

às vezes a leitura é um jogo de escala:

é preciso se aproximar a ponto de perder o todo

mas outras vezes é preciso se afastar muito do texto (GARCIA, 2018, p. 31-32).

A reflexăo da poeta é, nesse sentido, perpassada por essas referências de modos de ver. Em ambos os filmes, conforme reflete o próprio eu lírico, discute- se a questăo de algo que estava escondido, em segundo plano, e veio à tona através da fotografia, seja um sentimento, seja um mistério a ser resolvido. Há, dessa maneira, uma reflexăo que nos aproxima de um entendimento de fotografia debatido por Walter Benjamin (2017) na primeira metade do século XX. Para ele, existe algo na natureza que náo pode ser capturado pelo olho nu, mas que se revela, quando fotografado, trabalhando nosso inconsciente ótico:

A natureza que fala à câmera é diferente da que fala aos olhos. Diferente sobretudo porque a um espaço conscientemente explorado pelo homem se substitui um espaço em que ele penetrou inconscientemente. Se é vulgar darmo-nos conta, ainda que muito sumariamente, do modo de andar das pessoas, já nada podemos saber da sua atitude no momento na fraçăo de segundo de cada passo. Mas a fotografia, com os seus meios auxiliares - o retardador, a ampliaçấo - capta esse momento. Só conhecemos esse inconsciente óptico através da fotografia, tal como conhecemos o inconsciente pulsional através da psicanálise (BENJAMIN, 2017, p. 55).

Merece destaque, ainda, o fato da poeta se interessar pela "insistência e repetiçâo" que entende acontecer no filme Smoke. Essa prática está presente na lírica de Marília em diferentes níveis: a repetiçăo das fotografias diárias da pont marie, talvez a mais clara, uma vez que inspirada diretamente pelo filme; a repetiçăo das fotografias dentro da própria obra, "[você fala em ponte/ e traz várias imagens da mesma ponte]"; e, por fim, a repetiçăo dentro da própria poesia, os versos que se repetem ao longo do poema, e os versos de outros poemas que voltam para esse livro, constituindo uma repetiçăo também ao longo de sua obra. A poesia de Marília, em vários momentos, torna-se redundante e repetitiva. Esse movimento, porém, conforme vimos nas reflexóes da poeta, náo é arbitrário e busca causar um efeito de leitura, o qual atinge: a reflexăo sobre os métodos e modos de dar a ver. 
Vimos, ainda, nas estrofes citadas acima, que além das mençōes aos filmes, Garcia cita ainda Ricardo Piglia e Jorge Luis Borges. Ricardo Piglia, năo casualmente, analisa fotos de Borges quando este está quase cego. $\mathrm{O}$ eu lírico, entăo, compara esse movimento com a leitura, em um "jogo de escala", às vezes nos aproximamos e perdemos o todo, outras vezes nos afastamos e perdemos o detalhe. Nos interessa, entretanto, a maneira com a qual poeta utiliza o intertexto: Rose-Lynn Fisher, Debret, Georges Perec, Harun Farocki, David Perlov, Jacques Roubaud, Montaigne e Borges săo alguns dos nomes que ela menciona. Para Luciana di Leone, essa rede utilizada pela poeta constitui um método poético, "o método pelo qual o poema se dispóe a olhar o que está suspendido ao seu redor, o método da perplexidade ante as partículas de outros poemas, de outros discursos, de outros tempos" (2015, p. 131). Para a autora, nâo se trata ainda de investigar cada uma das citaçōes, já que a pergunta "a que se refere?" nâo é relevante aqui:

Ou seja, se encarado como desafio hermenêutico, o poema apareceria como hermético e endogâmico (duas caras da mesma moeda), e năo passaria de uma circulaçâo familiar de citaçôes, colocando o leitor no lugar do voyeur, sedento. Mas, ao contrário, a condiçâo de leitura que esse poema solicita é de um leitor já despido de toda vontade de gritar eureka; por isso năo é um poema didático, nem mimético, nem nada que ajude numa formaçăo (LEONE, 2015, p. 133).

Assim, năo é necessário partilhar do mesmo repertório da poeta para que haja um entendimento de seu texto. Marília rompe com aquilo que tradicionalmente é esperado de um poema, seja a utilizaçăo da citaçáo como forma de estabelecer parâmetros de leitura para o seu próprio texto, seja com a própria estrutura do verso e das estrofes, já que insere fotografias, colchetes, itálicos, diálogos, diários, cartóes postais e cenas de filmes em seu texto. As referências que a poeta utiliza, nesse sentido, estâo postas nâo como uma forma de dar continuidade a uma tradiçấo poética e se vincular a determinada corrente, mas como uma organizaçăo de vestígios e uma coleçấo de objetos e rastros.

Compreendemos, assim, que o poema, para Marília, é um lugar para pensar o próprio desenvolvimento lírico. O poema é lugar de reflexăo sobre a escrita e, portanto, pode ser editado, repensado, replanejado. De fato, ao longo de "Parque das ruínas", a poeta deixa explícito a existência de adiçóes e modificaçôes no poema, como na terceira estrofe, quando o eu lírico menciona que os versos que agora o leitor lê já foram apresentados anteriormente:

eu estava neste lugar

olhando a vista do parque das ruínas

quando chegou um e-mail de um professor da UERJ a universidade do estado do rio de janeiro

ele me chamava para um encontro

onde apresentei este texto que você está lendo (GARCIA, 2018, p. 15-16, grifo nosso).

Ao fazer mençăo ao processo de produçăo do poema nos próprios versos desse, a poeta nos revela que o processo é táo importante quanto o produto final, visto que ele é também matéria de poesia. Dessa forma, sua funçấo de produtora se torna evidente, 
náo há uma tentativa de esconder a figura do poeta, pelo contrário, a todo tempo somos lembrados que o poema foi escrito por alguém e que este alguém pode mudar as regras da leitura a qualquer momento. Épossível ver isso também no poema “o poema no tubo de ensaio", seçấo "[1,2,3 testando]":

\author{
quando comecei a escrever este texto \\ para uma jornada sobre o ensaio na unifesp \\ eu queria falar de um poema do escritor americano charles bernstein o poema era \\ um teste chamado "um teste de poesia" \\ eu queria começar falando daquele teste mas acabei sendo levada a falar de outro \\ teste (GARCIA, 2018, p. 59).
}

A imagem poética do "teste", ou ainda de "testar a poesia", que perpassa todo o poema, é interessante e contribui para nossa hipótese de que o processo da produçăo poética é uma questăo importante para poesia de Marília. Um teste é, afinal, um ensaio de alguma coisa que ainda năo está finalizada, que năo se tem certeza de como funcionará - uma análise no meio do processo. Em certa medida, é coerente a leitura de que os poemas de Marília săo eles mesmos testes: săo publicados antes de estarem finalizados (talvez nunca sejam finalizados) e, posteriormente, sâo republicados com uma série de dados acrescentados que, muitas vezes, indicam as circunstâncias em que o texto anterior ao atual se deu:"no dia em que falei este texto/tirei uma foto do auditório onde estava antes da fala -" (GARCIA, 2018, p. 48), "reescrevo esse texto quatro meses depois" (GARCIA, 2018, p. 60).

Vemos assim que, na poesia de Marília Garcia, as fronteiras entre poeta e eu lírico parecem ser constantemente borradas. As informaçóes biográficas e relatos da experiência de Marília se dissipam no meio de referências, reflexóes teóricas e procedimentos. Dessa maneira, percebemos que as reflexóes de Even-Zohar (2013a) sobre produtor parecem melhor dar conta de compreender este fenômeno. Sendo o produtor aquele capaz de produzir ideias, imagens e opiniōes, já năo é mais tăo importante a distinçăo entre eu lírico e eu biográfico. A produçấo de Marília confere novamente poder ao poeta, exige que este seja posto em evidência e deixa claro que o texto náo foi produzido no vácuo: há ali um eu que exige que seu nome, suas histórias, leituras e experiências sejam levados em consideraçấo no momento da leitura.

Percebemos, entâo, que essa lírica desestabiliza algumas das relaçóes de poder dentro da literatura, já que atribui ao produto-poema um papel tăo significativo quanto o do produtor-poeta. Aqui, a poeta nâo entrega seu poema aos leitores e é por eles esquecida em detrimento do texto: ela ainda detém poder sobre os poemas, já que os textos retornam modificados em livros diferentes, constituindo, assim, uma lírica que nunca está finalizada nela mesma. Náo se trata, entretanto, de ler o poema procurando por pistas da biografia da poeta, mas sim, de se ter como plano de fundo que as regras da leitura podem ser mudadas pela autora a qualquer momento.

Essa lírica, desse modo, exige da crítica e do leitor uma abordagem diferenciada, visto que, como apontado por Celia Pedrosa (2008), a contemporaneidade fragiliza critérios que antes tornavam a relaçáo entre público, crítica e obra estável. Para a autora, uma "pedagogia hegemônica fundada no cânone de grandes obras e autores" (2008, p. 41) năo teria mais viabilidade nem alcance na contemporaneidade. Em 
parque das ruínas, desse modo, encontramos uma poeta que brinca com as expectativas do leitor e entrega uma poesia fragmentada, que o tira da zona de conforto e o obriga à revisăo de conceitos, critérios e noçóes preestabelecidas sobre leitura, poesia e eu lírico. 


\section{REFERÊNCIAS}

BENJAMIN, W. Pequena história da fotografia. In: BENJAMIN, W. Estética e sociologia da arte. Trad. Joâo Barrento. Belo Horizonte: Autêntica Editora, 2017.

EVEN-ZOHAR, I. O sistema literário. Revista translatio, Porto Alegre, n. 5, p. 22-45, 2013a. Disponível em: https://seer.ufrgs.br/translatio/article/view/42900. Acesso em: 17 fev. 2020.

EVEN-ZOHAR, I. Teoria dos polissistemas. Revista translatio, Porto Alegre, n. 5, p. 1-21, 2013b. Disponível em: https://seer.ufrgs.br/translatio/article/view/42899. Acesso em: 17 fev. 2020.

GARCIA, M. Câmera Lenta. Săo Paulo: Companhia das Letras, 2017.

GARCIA, M. Parque das ruínas. Sáo Paulo: Luna Parque, 2018.

LEONE, L. Olhando a poeira: o método e a poesia de Marília Garcia. In: SCRAMIN, S; SISCAR, M; PUCHEU, A. O duplo estado da poesia: modernidade e contemporaneidade. Săo Paulo: Iluminuras, 2015.

RESENDE, B. Contemporâneos: expressóes da literatura brasileira no século XXI. Rio de Janeiro: Casa da palavra/Biblioteca Nacional, 2008.

SONTAG, S. Sobre fotografia. Trad. Rubens Figueiredo. Săo Paulo: Companhia das Letras, 2004 [Kindle edition]. 